\title{
Massive Open Online Courses and Formal Higher Education
}

\author{
Xingmin Shi ${ }^{1, a^{*}}$, Junmei Sun ${ }^{1, b}$ and Xuejiao Liu ${ }^{1, c}$ \\ ${ }^{1}$ Hangzhou Normal University, Hangzhou, P.R. China \\ ashixingmin@hznu.edu.cn, bjunmeisun@hznu.edu.cn, cliuxuejiao0406@163.com
}

Keywords: massive open online courses; formal education; higher education; teaching method

\begin{abstract}
With the rapid development of MOOC worldwide, traditional formal higher education of college is facing huge challenges due to the innovative learning method provided by MOOC. MOOC promise an effective learning method in a free style, either in course selection or the process control of learning. And the most important is that it is free to learn excellent courses offered by famous universities. For traditional higher education, the benefits of MOOC can be utilized for reference. The trackable learning process, diverse assessment methods, as well as the communitive online interaction, can effectively improve the teaching result in formal teaching and learning. However, there are still some issues to be solved, such as the imperfect online forum for Q\&A, plagiarism and dishonesty in learning, and discipline limitation in course selection.
\end{abstract}

\section{Introduction}

With the increment of web-based learning and the development of mobile technology, massive open online courses (MOOC) attract much attention of educators and academic researchers. MOOC starts from the time when Stanford University offered five courses online in the fall of 2011 and Udacity, a MOOC corporation, begin to provide online services [1]. Then edX was born, and lots of platforms are built for various types of learners by universities or business companies engaging in education service. Online education has become a hot topic either for education researchers or commercial companies.

Currently available MOOC platforms, such as Udaciy, edX, Coursera, etc. offer lots of high-quality courses on various subjects. In addition, MOOC break the limitation of learning method, and anyone can learn the course interested in without considering requirements of time and location. It provides you with massive courses in an open way, and you can learn them online anytime and anywhere. Furthermore, most courses come from eminent professors in the top universities in the world. As a result, the course content attracts lots of participants all over the world, including college students worldwide.

MOOC carries huge benefits for those who wants to extend personal knowledge. They can learn what they want to explore by participating to the best course in the world through the network. Moreover, participants who completed the course was able to learn autonomously and navigate the distributed platforms and environments [2]. It means the professional personality can be considerably improved by learning MOOC courses. MOOC offers unprecedented opportunities for lifelong learners, as well as campus education.

MOOC develops rapidly in recent years, and meanwhile, formal higher education still keeps the traditional way of teaching and learning. The occurrence of MOOC has brought tremendous impact on traditional formal higher education in universities. Traditional educational institutions and educators need to think about if the pattern of MOOC course can be used in formal higher education or even replace the traditional educational method. If MOOC can serve campus learners and bring great benefits to the classroom. MOOC provides educators an opportunity for the reform of teaching method in formal higher education [3].

The rest of this paper is organized as follows. Firstly, key features of MOOC learning are introduced. Then, the benefits of the application of MOOC in higher education will be presented and discussed. A summary is done finally. 


\section{Features of MOOC Learning}

Formal higher education is a regulated learning process, in which the learning progress is under the supervision of instructors at the fixed time and space. Comparing with traditional learning method, key features of MOOC learning are as follows.

Firstly, MOOC learning is global. One of the most appealing factors is that participation in MOOCs allowed learners to hear from a global voice. Most of the instructors of MOOC courses are knowledgeable, organized, and well respected in their field.

The learning schedule is flexible enough. Participants can access their course at any time, from anywhere. This means that MOOC provide individuals, either college students or employed person, the option of attending classes no matter their work schedule for personal development [4]. It gives participants the flexibility to take what they want rather than at a set time every week. Individuals have diverse options in course selection. Leaners are capable of selecting courses from diverse degree programs or select the course service when the same course is offered by various institutions. And students can make their own decision to access the content or complete assignments at their own time and pace.

Learning resources are easily accessed. Courseware and lecture videos can be accessible when need it. You can download them for learning offline, or use them online freely. The process of MOOC learning is fragmented. The learner can start or stop learning anytime when need. Furthermore, no physical textbooks are needed in MOOC learning, all course materials are provided in an electronic way, and e-textbooks can offer substantial savings for students.

Another benefit is the case that the facilitation of dealing course questions. Most MOOCs had weekly activities such as guest presenter, Q\&A sessions, or project help sessions. The interactive communication can ease the learning process, especially when there is a difficult question to solve. And at the same time, the communication skills can be improved gradually.

\section{MOOC and Higher Education}

According to a 2014 survey of tracking online education in the United States conducted by the Babson Survey Research Group [5], distance enrollment of public and private nonprofit institutions is growing. Percent of academic leaders rating the learning outcomes in online education at the same or superior to those in face-to-face is $74.1 \%$. The proportion of chief academic leaders who believe that online learning is critical to their long-term strategy reaches a new high of $70.8 \%$. However, only $8.0 \%$ of higher education institutions currently offer one, another $5.6 \%$ report that MOOC is in the planning stages.

For educational institutions that are currently developing and offering MOOC courses, the main motivation is that they want to improve educational outcomes, innovate teaching and learning, and conduct research on teaching and learning [6]. Depending on the study on the feasibility of using MOOCs as a learning environment in academic courses presented in [7], the scope of student activity, the learning intensity, and learner path are tracked and analyzed. The investigation result shows that students are very satisfied with their learning process and relatively high grades. Lecturers are very enthusiastic and satisfied with the innovative teaching mode. And the academic environment is innovated by integrating this new model of learning.

As aforementioned advantages of MOOC, for the sake of improving teaching result, it is feasible to incorporate superior MOOC patterns into the existing teaching process in formal higher education. First of all, the offering of MOOC course provides an efficient way of keeping, maintaining and improving teaching materials continuously. Lecturers can provide necessary course materials, including video, courseware, text of assignments, references, and maintain them in the process of learning. In addition, participants can share private materials related to the course with others online.

The trackable learning progress is another benefit that can be gained with MOOC course. MOOC platform makes it possible to track the status of course selection, completion status, learning path and learning intensity. The learning process is under an effective supervision, and thus MOOC promises 
another option of assessment method [8], which allows the instructor track student progress anytime, anywhere. The only limitation lies in that if there is an available network connection.

It is easy for teachers to grade homework or assess the work of students online [9], and the assessment results can be kept and analyzed automatically. Besides traditional assessment method, the paper test up to instructors, various assessment approaches are available in MOOC. In addition to the conventional teacher assessment, the type of assessment can be self-assessment, peer assessment, as well as automatic assessment with automation technique support [10][11]. Moreover, those assessment techniques in MOOCs can help to maximize the final learning outcomes.

The learning process in MOOC platform is self-regulatory [12]. The learner should make his own study plan independently according to his own schedule. The learning process is free from the supervision of formal education. MOOC is going to help people who are self-motivated and already have realized how to learn. They will assist those who can already help themselves. Consequently, learning of MOOC course can cultivate and improve the self-regulatory capability of students. The formal education is appropriate for those who can't yet help themselves, don't know how to study, don't know enough what they want, or what they should learn. They need to be more or less confined in an environment where they can be guided to learn how to learn. This is what formal higher education is expected to be.

\section{Discussion}

According to a recent study by Columbia University, MOOCs will not fundamentally reshape higher education, nor will they disappear altogether [13]. It partly lies in that there are still some challenging issues to be addressed in the future though MOOC can bring lots of benefits to formal higher education up to a point.

With online experiments, homework deadlines, midterm and final examination, students can feel that the MOOC was like taking a real course. However, interactive stimulation is still necessary to initiate learning effectively [14]. When there is a question about the course to be solved or fail to understand the content, it is difficult to turn to someone for help online in time. Moreover, the discussion board of MOOC is considered to be a little disappointment because most threads consisted of little more than a posted question that the instructor had answered. In contrast, the traditional face-to-face Q\&A is more approachable and practical.

In addition, MOOC is not appropriate for all courses of all disciplines. The courses of computer science-related discipline are more likely suitable for being offered in MOOC platform. Another worry is the student plagiarism and dishonesty in learning MOOC courses. Some critics believe that it is easier to plagiarize or share answers because of reduced surveillance and increased connectivity. Moreover, as the most widely applicable approach for all MOOCs, peer assessment can give the essential feedback. However, uncontrollable peer assessment results tend to suffer from a lack of credibility. Consequently, institutions should try to find possible ways to fight against these concerns with existing technologies.

Another controversy is that online degree programs are viewed as less optimal instruction for students, with no real standards to regulate the curriculum. However, online instruction is subject to academic scrutiny like on-campus schooling.

\section{Summary}

With the rapid development of MOOC, the learning pattern of MOOC increasingly demonstrates its power in personal learning. Flexible schedule, massive optional courses and easy access to courseware attract a large quantity of learners worldwide. Though formal higher education was strongly affected by the occurrence of MOOC, it is still the main stream of formal educational method. The integration of formal education and MOOC provide a well complementary method which can improve the prescribed teaching method. The improvement of formal education would occur directly 
within the MOOC patterns and indirectly through the transfer of new strategies and techniques to campus learning.

\section{Acknowledgement}

This work is supported in part by the fund of the Teaching Reform Projects of Hangzhou Normal University, 2014.

\section{References}

[1] Tharindu Rekha Liyanagunawardena, Andrew Alexandar Adams, Shirley Ann Williams, MOOCs: A Systematic Study of the Published Literature 2008-2012, International Review of Research in Open and Distance Learning. 14 (2013) 202-227.

[2] Jenny Mackness, Marion Waite, George Roberts, Elizabeth Lovegrove, Learning in a Small, Task-Oriented, Connectivist MOOC: Pedagogical Issues and Implications for Higher Education, International Review of Research in Open and Distance Learning. 14 (2013) 140-159.

[3] Fasimpaur, Karen, Massive and Open, Learning \& Leading with Technology. 40 (2013) 12-17.

[4] Tawanna Dillahunt, Zengguang Wang, Stephanie D Teasley, Democratizing Higher Education: Exploring MOOC Use among Those Who Cannot Afford a Formal Education, International Review of Research in Open and Distance Learning. 15 (2014) 177-196.

[5] 2014 Survey of Online Learning on http://onlinelearningconsortium.org/read/survey-reports-201 4/

[6] Fiona M. Hollands, Devayani Tirthali, Why Do Institutions Offer MOOCs?, Online Learning, 18 (2014) .

[7] Tal Soffer, Anat Cohen, Implementation of Tel Aviv University MOOCs in Academic Curriculum: A Pilot Study, International Review of Research in Open and Distributed Learning. 16 (2015) 80-97.

[8] Todd A. Finkle, Evan Masters, Do MOOCs Pose a Threat to Higher Education?, Research in Higher Education Journal. 26 (2014) 1-10.

[9] Wilfried Admiraal, Bart Huisman, Olga Pilli, Assessment in Massive Open Online Courses, Electronic Journal of e-Learning. 13 (2015) 207-216.

[10] Chauhan, Amit, Massive Open Online Courses (MOOCS): Emerging Trends in Assessment and Accreditation, Digital Education Review. 25 (2014) 7-19.

[11] Erin Dawna Reilly, Rose Eleanore Stafford, Kyle Marie Williams, Stephanie Brooks Corliss, Evaluating the Validity and Applicability of Automated Essay Scoring in Two Massive Open Online Courses, International Review of Research in Open and Distance Learning. 15 (2014) 83-98.

[12] Colin Milligan, Allison Littlejohn, Supporting Professional Learning in a Massive Open Online Course, International Review of Research in Open and Distance Learning. 15 (2014) 197-213.

[13] Kolowich, Conventional online education will absorb MOOCs, 2 report says on http://chronicle.com/blogs/wiredcampus/conventional-online-higher-education-will-absorbmoocs-2 -reports-say/52603?cid=at\&utm_source=at\&utm_medium=en

[14] A. Agarwal, 'Circuits and Electronics', MITx, Chronicle of Higher Education. 59 (2012) B10. 